\title{
GENERATION, DETECTION AND PROPERTIES OF COHERENT RADIATION OF WAVE-LENGTHS LESS THAN I MM
}

$\mathrm{T}$ HE sutumn moeting of the British Radio Spectroscopy Group was held at Bournemouth, Hempshire, during September 24-25. The meeting was concerned with the generation, detectirsn and properties of coherent radiation of wave-lengths less than $1 \mathrm{~mm}$. Nineteen papers were presented during three sessions while the fourth session was taken up with a visit to the Quanturn Physics Division of the Signals Research and Development Establishment, Christchurch, Hampshiro.

Mr. R. J. Lees, diroctor of tho Signals Research and Development Establishment, who gave the address of welcome to the 130 delegates, comprising approximately 45 from the universities, 55 from industry and 30 from Government service, saw the essential function of the moeting to enable the delegates to exchange ideas on mutual intorosts, so forming cross-linkages botween the various sections of this wide fiold.

The nineteen papers presented can be divided into four general groupings, eleven on generation, two on detection, three on spectroscopy and three concerned with gaseous lasers. As can be seen, the generation of sub-millimetre radiation attracted the most attention.

M. G. Convert (Compagnie Générale de Télégraphie sans Fil) diseussed the main design features: beam geometry, beam velocity and construction of the elements that have to be considered in the development of a carcinatron. The power output, which depends approximately on the reciprocal of the frequeney squared, is limited by the imperfections in them together with any ohmic losses. Results were presented of output power against wave-length for a range of volues. In particular the 0-5. $\mathrm{rnm}$ carcinatron gave a few milliwatts and had a 10 per cent tuning renge.

Dr. K. D. Froome (National Physical Laboratory, Teddington) outlined the design of his plasma-metal junction harmonic generator. It rectifies and therefore gonorates harmonics by field omission from a liquid platinum eathode due to the proximity of a very dense plasme. This plasma is formed in an argon-hydrogen atmosphere at high pressure and has an ion density that has to be kept to less than $10^{20}$ in order to avoid back conduction. When the junction was driven with $10 \mathrm{~W}$ at $8 \cdot \tilde{5}-\mathrm{mm}, 0 \cdot 3-\mathrm{mm}$ radiation, the twenty-ninth harmonic, was generated.

Tho construction and operation of sueh a generator as a tunable source in a high-resolution sub-millimetre spectrometer was described by Mr. J. Knapp (Queen Mary College). It was found not practical to use it in an automatic scan system. Dr. A. J. Bastin (Queen Mary College) reported measurements made by a number of workers, inchuding himseif, of atmospheric absorption in the sub-millimotre rogion. These measurements showed that atmospherie absorption was due to: (1) water vapour broadened by nitrogen collisions; (2) water droplets of varying radii; (3) oxygen, ozone and other trace gases; (4) collision-induced absorption between oxygen and nitrogen atoms. It was cornmented that more experiments were needed in which some attempt had been made to mateh path-length to absorption coefficients.

Mr. G. S. Waters (Signals Research and Dovelopmont Establishment) described the construction and operation of an optical line-of-sight communication link using a helium noon laser on $6328 \&$ as source. Measurements were made comparing the laser as a souree with a mereuryare lamp, both being shone 'backwards' through a mirror telescope over 1,300 yd. The results showed that the spatial coherence of the laser made the laser superior to the are lamp for ranges longer than $300 \mathrm{yd}$. The laser's narrower line-width seerned to be only of secondary importance. Dr. D. C. Laine (Keele) examined the feasibility of an ammonia maser oscillating at $0.125 \mathrm{~mm}$ on the $J=4, K=3$ to $J=3, K=3$ rotational transition. A relation was derived giving the minimum number of molecules required per sec for oscillation threshold. The substitution of values into this relation gave that the number required was a factor two thousand times larger than the number needed in the microwavo ease. This factor oan only be obtained by the use of multiple beams.

Dr. J. G. Baker (Bristol) discussed the spoetroscopy of short.lived free radicles and gases in the lower millimetre and sub-millimetre regions. A free-space absorption cell suitable for the observation of electric and magnetic rotational transitions, many of which fall in these regions, was described togothor with a superheterodyne system of detection. Mr. A. W, Horsley (Standard Telecommunication Laboratories, Ltd.) discussed two possibilitios for generating sub-millimotre radiation using bulk non-linear properties of semi-conductors. The first rested on charge density gradients and electric field gradients in the semi. conductor giving rise to harmonie currents. Tho second involved the mixing of axial modes in laser beams by an extensior of Pantell's contimetre wave mixing techniques. Mr. C. H. Carmichael (Signals Reserrch and Development Establishment) proposed the use of a Fabry-Porot etalon within the parallel mirror resonant cavity of a laser to suppress the emission except within the narrow pass bands of the etalon. Then with a laser material, the fluoreseence line width of which is $10 \mathrm{~cm}^{-1}$ or greater, the plate separation of the etalon can be chosen to yield frequencies, which, when mixed in a suitable non-linear system, will yield sub-millimotro radiation.

Mr. I. B. Bott (Radar Research Establishment) deseribed the construction of a tunable souree of millimetre radiation $0.93-2 \mathrm{~mm}$. Electrons, whon injected into an axially symmetric magnetic field, undergo cyelotron resonanee and the radiation emitted in a strong forward lobe is partially coherent. In the case described the field was pulsed to $100 \mathrm{kG}$ and remained reasonably stoady for 7 msec. The output at $1.1 \mathrm{~mm}$ was $1 \mathrm{~mW}$. Mr. A. H. Beck (Cambridge) suggested that a spiralling electron beam when synchronized to an electric field having the correct time dependence should be a mothod of generating millimetre radiation. Mr. P. M. Robson (Sheffield) suggested that millimetre radiation could be generated by Doppler shifting radiation from a moving mirror of lowvoitage electrons. If the electrons were to be bunched at the matching frequency then both the electron mirror's reflectance would be inereased and thore would be some harmonic output. Dr. J. V. Jelley (Atomic Energy Research Establishment) discussed the use of Cerenkov radiation as a source of sub-millimetre waves. A Fourior analysis of the radiation produced as electrons are fired through a dielectric shows that there is a component at a sub-millimetre frequency. This component may be enhanced by bunching the electrons at the required frequency. This mothod has producod $20 \mu \mathrm{W}$ at $1.6 \mathrm{~mm}$.

Mr. M. A. C. S. Brown (Radar Research Establishment) described two possible tunable detector mechanisms; one depending on changes in number of carriers and the other depending on changes of carrier mobility, Both these mechanisms are suitable for use in narrow band far infres. red detectors. A description of tho indium antimonide detector was given together with its narrow-band eharacteristics. 
Dr. M. R. Brown (Signals Research and Development Establishment) gave a brief report on the observation of infra-red quantum counter action in praseodymium doped fluoride lattices at room and liquid nitrogen temperatures. It was hoped to use the reported schemes as a basis for the development of an infra-red detector. Mr. D. M. Clunie (Services Electronies Research Laboratory) reported results of some experiments on helium-neon gas mixtures in which more power was obtained under pulsed conditions than under continuous excitation. This was attributed to the population in the laser terminal level being higher under the continuous excitation. Furthermore, by having two sections separately pulsed at $2.5 \mathrm{kc} / \mathrm{s}$ a continuous output at $0.25-\mathrm{W}$ mean level was obtained. Doubling of the infra-red outputs in ammonium dihydrogen phosphate to give a yellow spot was announced. Mr. J. Smith (Mullards) reported gain measurements made in heliumneon gas mixtures using the $1 \cdot 15 \mu$ laser line. It was found that the optimum gain in the negative glow region of a cold-cathode glow discharge within a hollow cathode was achieved at much higher pressure (20-mm mercury) and higher helium to neon ratios $(1,280: 1)$ than those used in radiofrequency or direct-current positive column excited devices.

Dr. E. L. Thomas (Signals Research and Development Establishment) oxplained the stimulated Raman effect and its use in the generation of radiation. When benzene is placed inside the resonant cavity of a ruby laser, stimulated Raman radiation is produced $991 \mathrm{~cm}^{-1}$ away from the ruby frequency. A second Raman radiation can also be generated approximately $1,982 \mathrm{~cm}^{-1}$ away. The submillimetre radiation, in this case $0.01 \mathrm{~mm}$, would then be generated by mixing the Raman radiation with the ruby radiation.

Dr. D. H. Martin (Queen Mary College) reviewed the kinds of spectra that can be observed in solids with submillimetre radiation. These ranged from lattice absorptions in ionic lattices ( $30 u$ for lithium fluoride) to antiferromagnetic resonance ( $1 \cdot 2 \mathrm{~mm}$ for manganous fluoride). M. R. BROWN

\section{THE GEOLOGISTS' ASSOCIATION}

CEVERAL important geological finds made during S 1963 were among the exhibits shown at the annual reunion of the Geologists' Association held in the Large Hall of Chelsea College of Science and Technology on November 2.

The most outstanding of these discoveries was the remains of a large plioseur from the Oxford Clay exhibited by the Department of Palæontology, British Museum (Natural History). This comprised a right-hand paddle $7 \mathrm{ft} .6$ in. in length. Many pliosaurs have been found in the Oxford Clay especially near Peterborough ${ }^{1}$. However, complete specimens of large pliosaurs lying in situ are rarely come by. It is thought their size prevented them from quickly sinking in the mud and hence they were eaten by thoir fellow scavengers. The pliosaur was found in the London Brick Company's clay pits at Stewartby, Bedfordshire, during June 1963, but the front half of the reptile had been taken away by the digger before the bones were noticed. Some of thom were later recovered from the spoil heap by a party from the British Museum (Natural History), and the London Brick Co. has presented the remains to the Museum. It is hoped that the whole reptile will be recovered. The British Museum (Natural History) also showed dinosaurian footprints from the Purbeck, Devonian trilobites from the Spanish Sahara and cobalt pellets from the stomachs of sheep.

In 1961 the longest continuous trackways yet found were discovered in a quarry at Herston on the outskirts of Swanage, and in June 1963 after the overburden had been removed $75 \mathrm{ft}$. of trackway was exposed. Until now it has been generally assumed that these footprints were made by the horbivorous bi-pedal dinosaur, Iquanodon. But, as shown by the exhibit, it is apparent that the birdlike prints forming the main trackway are more akin to a bi-pedal carnivorous dinosaur, such as Megalosaurus. Until recently, trilobite remains were almost unknown from the Spanish Sahara, but during oil exploration work there E. Rod collected almost 30 specimens. The best were given to the British Museum. They came from strata of the Middle Devonian and all belong to the genus Phacops. With the exception of a single specimen they belong to one species, probably new but related to $P$. papulatus from Morocco. The remaining specimen is a related form but is distinguished by a finer ornamentation of the test and a large number of eye facets.

S. E. Ellis (Department of Mineralogy) exhibited phosphate minerals deposited on cobalt pellets from the stomachs of sheep. The sheep is subject to a disease known as 'pining' due to a deficiency of cobalt in herbage. This is combated by either the expensive method of spraying or inserting into the young lamb's stomach a pellet of baked clay impregnated with cobalt oxide.

Ammonites and literature recently acquired in the U.S.S.R. were among the items shown by the Geological Survey and Museum. Ammonites are very important in the identification of zones or sub-zones, which are often named after them. They included the following species from the Upper Aptian of the Lower Greensand (Lower Cretaceous): Parahoplites melchioris, Colombiceras caucasicum and Australiceras ramososeptatum.

J. N. Carreck (Queen Mary College, London) showed specimens, maps, etc., illustrating copperas, as vanished Kentish industry. From about A.D. 1320 until 1914, copperas (an obsolete name for ferrous sulphate or green vitriol) was manufactured from iron pyrites occurring in the London Clay (Lower Eocene) on parts of the coasts of Essex $^{2}$, Kent, Dorset and, perhaps, Hampshire. It was used for the preparation of sulphuric acid, black ink and dye (both as a pigment and a mordant), dressing leather, as a sheep die, for the making of paints-prussian blue (ferric ferrocyanide) and spanish brown (ferric hydroxide), and after refinement was in much demand among both apothecaries and physicians. Mrs. Carreck exhibited photographs of past and present members of the Association.

Dr. G. P. L. Walker (Imperial College of Science and Technology, London) showed several xenoliths of wood collected from Tertiary basalt larvas. He explained how timber, when enclosed in basalt, chars and the basalt is consequently injected into the network of contraction cracks which result. Sometimes the charred wood survives; at other times it is fossilized, for example, replaced by zeolites; or it disappears to leave cavities in the basalt and these may afterwards be infilled with zeolites, etc.

With the west Weald earthquake of October 25 and the Glen Spean earthquake of August 31 still in the news, Dr. A. T. J. Dollar (Birkbeck College, London) exhibited a map illustrating the intensity of the quakes, together with data based on reports from observers of the British Earthquake Enquiry. Other earthquakos demonstrated in the same manner were those occurring in the County of Inverness in 1947 (ref. 3) and the Midlands in 1957 (ref. 4). Together with F. G. Berry, Dr. Dollar also showed a new hand-operated continuous coring tool with a sample core.

A. G. Nicholson showed specimens illustrating tho geology of the Lizard Peninsula. These included the 'serpentine' of the local lapidaries which is the altered 